on them when they were very far from the sun, they then being simply white. I did not see any dark ones, as described by J. E. Clark; indeed they always struck me as being very thin, merely like a nearly flat sheet. They tended to be arranged in bands like "Noah's Arks," and, while their texture was smoother than most cirrus clouds, they were more or less striated transversely. On some afternoons I noticed in many cases a feeble smoke-like prolongation, or tail, on the cast side of the cloud; this had no colouring. They had thus sometimes a striking resemblance to an aurora, differing essentially, however, in their real position being horizontal, while the auroral band and rays are almost vertical. Their direction also was quite different: on the IIth at $8.15 \mathrm{a} . \mathrm{m}$., and I th at $3.40 \mathrm{p.m}$. I noticed that the strix pointed to east by south. In shape they approached parailelograms apparently; really, to rectangles; sometimes they were very perfect rectangles. One of the most striking clouds was, however, a perfect right-angled triangle in form. Their motion was very slow. Some time after sunset they were so bright as to give a material amount of light, and to make the dust-circle around the sun look quite dim. They were evidently at a great height, though they looked lower than the dust-wisps. They were incapable of producing an ordinary halo.

Like Prof. C. Piazzi-Smyth, I can say that I have no recollection of seeing any clouds of the kind before. I saw nothing like them at the time of the grand sunsets last autumn, and I think he is mistaken in supposing any of the phenomena then seen were of the same character.

Sunderland, December 22, I884

REFERRING to the letters which have appeared in these columns on the subject of "Iridescent Clouds" as seen at Edinburgh and York on the evening of December II, a very similar phenomenon was seen at Derby at sunrise on that day, and was thus described in the Derly Express the same evening :"About half an hour before sunrise the castern half of the sky was covered with a dense pallitum of cirrus cloud. About $30^{\circ}$ above the horizon was seen what appeared to be an elongated opening in the dark grey of the clond. Through this spindleshaped opening the sky. was of an intense emerald colour. The strangest part of the phenomenon, however, occurred shortly before eight o'clock, when the vivid green had given place to a mass of brightness comprising all the prismatic colours arranged in bands transversely, each of the primary colours shading gradually into its neighbour in the same manner as in a solar rainbow. The appearance was now not unlike a huge manycoloured eye set in a dark uniformity of cirro-stratus. As the sun arose the colouring faded, and when the solar orb was several degrees above the horizon the phenomenon remained as a patch of brightness upon a silver-grey vapour, and was somewhat similar in appearance to an imperfectly formed parhelion. Its position, however, with regard to the true sun, showed at once that the phenomenon was not of the parhelion class."

C. J. P.

THE iridescent cloud effect mentioned by your correspondents (see NATURE, p. 148) was well seen here on the $13^{\text {th }}$ about 4 p.m., and was very much as described by Mr. Clark. Three distinct bands of colour were seen just at the upper edge of a dark slate-coloured cloud towards south-west, and two faint ones on the clearer sky above. I write specially to remark on the nature of the colour of these bands. They were not prismatic colours as mentioned by Mr. Clark, but unmistakable interference or residual colours, the lowest bright purplish pink, shading into green, the next the peculiar light brick red seen in Newton's rings, and a very recognisable colour, also shading into green, and the rest pink and green, of similar colour to the lowest. There can be, I thiuk, no question that this was an interference-phenomenon, and I hope some of your correspondents may be able to give the rationale of it.

Fairfield House, Darlington

JAMES I'ANSON

I SEe notes in NATURE, December 18,1884 (p. 148), on iridescent clouds. I observed similar appearances on the Yorkshire Wolds, between Market Weighton and Brough, on December 6 and again on December 13,3-4 p.m. ; but instead of the clouds being totally coloured, only the edges of rifts in a thick cloud-mass were so tinged. The phenomenon was much finer on the latter date, the rift being much larger and the colours more widely dispersed at one end, so that a rose tinge occupied there the whole of the acute angle of the gap. Broseley, Shropshire W. W. WatTs

\section{The Rotation of Neptune}

SEVERAL circumstances delayed my observation of the planet Neptune this autumn until November 24. On that and the two following nights the light of Neptune was compared with the light of the star B.A.C. 1072 ; and, assuming that the light of the star was steady, that of Neptune was found to undergo apparently regular variations, but much smaller than they were last year.

The observations were combined in the following manner :-The magnitude, $m$, at any time, $t$, was assumed equal to

$$
m_{\mathrm{o}}+k \sin n\left(t-t_{\mathrm{o}}\right) \text {, }
$$

where $m_{0}$ was the mean magnitude at the time $t_{0}, k$ one-half the variation between maximum and minimum, and $n$ equal to $\frac{360^{\circ}}{7.92}$, or $45^{\circ} 45$, according to the observations of Neptune last year, which gave $7.92 \mathrm{~h}$. as the rotation-period. Subtracting $m^{\prime}$, the unknown magnitude of the comparison star, which is, however, of about the seventh magnitude, we have

$$
m-m^{\prime}=m_{\mathrm{o}}-m^{\prime}+k \sin n\left(t-t_{\mathrm{o}}\right) ;
$$

and by assuming approximate values, by introducing corrections, and by solving the II equations corresponding to the I I observations by the method of least squares, it was found that

$$
\begin{aligned}
m_{\circ}-m^{\prime} & =0.86 \\
k & =0.19 \\
t_{0} & =\text { Nov. 24d. 13.0rh. G.M.T. }
\end{aligned}
$$

The preceding epoch of maximum will be found by subtracting I. $98 \mathrm{~h}$. ; and similarly the following epoch of minimum will be found by adding $\mathrm{I} \cdot 98 \mathrm{~h}$.

Now these observations were made without special care, and consequently the probable errors were larger than they should be in comparison with the small variation; but on the night of November 29 every care was taken to obtain accuracy in the photometric measures, and the following results were obtained :-

\begin{tabular}{|c|c|c|c|c|c|c|c|}
\hline Kempsh & $\begin{array}{l}\text { ot } \mathrm{M} \\
\text { Tov. }\end{array}$ & & & $\begin{array}{l}\text { ff. } m \\
-1\end{array}$ & & & o $-\mathrm{C}$. \\
\hline & m. & & Obs. & & Comp. & & \\
\hline 7 & I0 & & 0.91 & $\ldots$ & 0.92 & $\cdots$ & - O.OI \\
\hline 8 & 26 & $\ldots$ & I.03 & $\ldots$ & $1^{\circ} \mathrm{O} 2$ & $\ldots$ & +0.01 \\
\hline IO & 5 & $\ldots$ & 0.88 & $\ldots$ & 0.88 & ... & $0^{\circ} \infty 0$ \\
\hline I2 & 7 & $\ldots$ & 0.64 & $\ldots$ & 0.63 & $\ldots$ & +0.01 \\
\hline
\end{tabular}

$$
\begin{aligned}
m_{\circ}-m^{\prime} & =0.82 \\
k & =0.20 \\
t_{0} & =\text { Nov. 29d. II } 72 h . \text { G.M.T. }
\end{aligned}
$$

The following is the comparison of observation and computation :-

It should perhaps be added that Kempshot is $5.19 h$. west of Greenwich.

By comparing the epoch on November 29 with the corresponding epoch on November 24 , we find that 15 rotationperiods occupy $118^{\circ} 7 \mathrm{I} h$., so that each rotation-period is $7^{\circ} 914 \mathrm{~h}$., which may be considered identical with the period found last year.

$$
\text { MaXWell MaLL }
$$

Jamaica, December r, 1884

\section{Peculiar Ice.Forms}

Circumstances have prevented my replying earlier to Dr. Rae's letter in NATURE of November 27 (p. 8I). The situation of the ice described in my letter of November 6 (p. 5) precludes the possibility of its having been a remainder from last winter's snow, since it was only some fifteen hundred feet above the valley of Chamounix, and exposed during the summer months to daily sunshine. In fact, the mid-day sun only just failed to reach it on the $I 7$ th of October.

In the Neues Jahrbuch fiur Mineralogie for 1877 (referred to by Dr. Wetterhan of Freiburg in NATURE, vol. xxi. p. 396) is an article by Dr. G. A. Koch giving an elaborate description and discussion of a very similar ice-structure, formed under very similar circumstances, which he observed on October I8, 1875, near St. Anton in the Arlberg. He also quotes other cases observed on the Wormserjoch in the Tyrol, and by Prof. Doenitz 